\title{
Evidence-based and tailored medication in type 2 diabetes: a pathway learned from clinical trials
}

\author{
Atsushi Tanaka* (10 and Koichi Node
}

\begin{abstract}
In Japan, the choice of anti-diabetic medication is officially recommended according to the patient's glycemic condition and disease phenotype, unlike most other regions where metformin is recommended as the first-line medication. There has been an increase in the number of available glucose-lowering agents, making it necessary to select these agents based on ever-improving evidence obtained from clinical trials. For the dipeptidyl peptidase-4 inhibitor class of drugs, nine drugs are currently available on the market in Japan. Although previous cardiovascular outcome trials (CVOTs) demonstrated non-inferiority for both major adverse cardiovascular events (MACEs) and safety for some drugs of the class, the design and results of the CARMELINA trial seemed to be slightly different from earlier trials in that it showed the drugs were safe and partially effective even in patients with renal impairment. Thus, recent CVOTs on newer glucose-lowering agents have mainly focused on the major impacts of individual classes and drugs on clinical outcomes behind their glucose-lowering action. The diverse features of the classes and individual drugs may have also highlighted not only the class-effects, but also the drug-effects of glucose-lowering agents. This will lead to clinical-based evidence and assist with optimum selection of the class and/or drug for tailored medication in patients with type 2 diabetes.
\end{abstract}

Keywords: Type 2 diabetes, Cardiovascular outcome trial, Glucose-lowering agent, Dipeptidyl peptidase-4 inhibitor, Tailored medication

An important clinical question is whether it is possible or a clinical requisite to use glucose-lowering agents within a class of drug differently in different patients. Prior to the CARMELINA study, all dipeptidyl peptidase-4 inhibitors (DPP-4is) appeared to have similar clinical impacts on non-glycemic parameters. That study demonstrated that linagliptin treatment did not increase the risk of composite major adverse cardiovascular events (MACEs) and also met the authorities' requirements for cardiovascular safety of glucose-lowering agents [1] similar to that reported for other DPP-4is [2]. An important finding was that linagliptin was proven to be effective even in patients with long-standing type 2 diabetes (T2D) associated with renal impairment. This efficacy had not been observed

*Correspondence: tanakaa2@cc.saga-u.ac.jp

Department of Cardiovascular Medicine, Saga University, 5-1-1

Nabeshima, Saga 849-8501, Japan in previous major studies on DPP-4is. Of further note was that the CARMELINA study also showed slight but intriguing differences in some cardiovascular and renal outcomes from those reported by previous trials.

It is noteworthy that linagliptin treatment prevented the progression of urinary albumin excretion significantly. As stated earlier, the CARMELINA trial specifically included adults with a lower estimated glomerular filtration rate (eGFR) compared to those in previous studies, with $43 \%$ of participants in the trial having at least a moderate to severe $\left(<45 \mathrm{~mL} / \mathrm{min} / 1.73 \mathrm{~m}^{2}\right)$ decline in baseline eGFR. The mechanism of how linagliptin ameliorated the deterioration in renal function remains unclear, although it is possible its extrarenal excretion and unknown drug-specific effects may potentially have been involved in its beneficial effect on renal function [3]. However, detailed data from a head-to-head cardiovascular outcome trial (CVOT), the CAROLINA [4], 


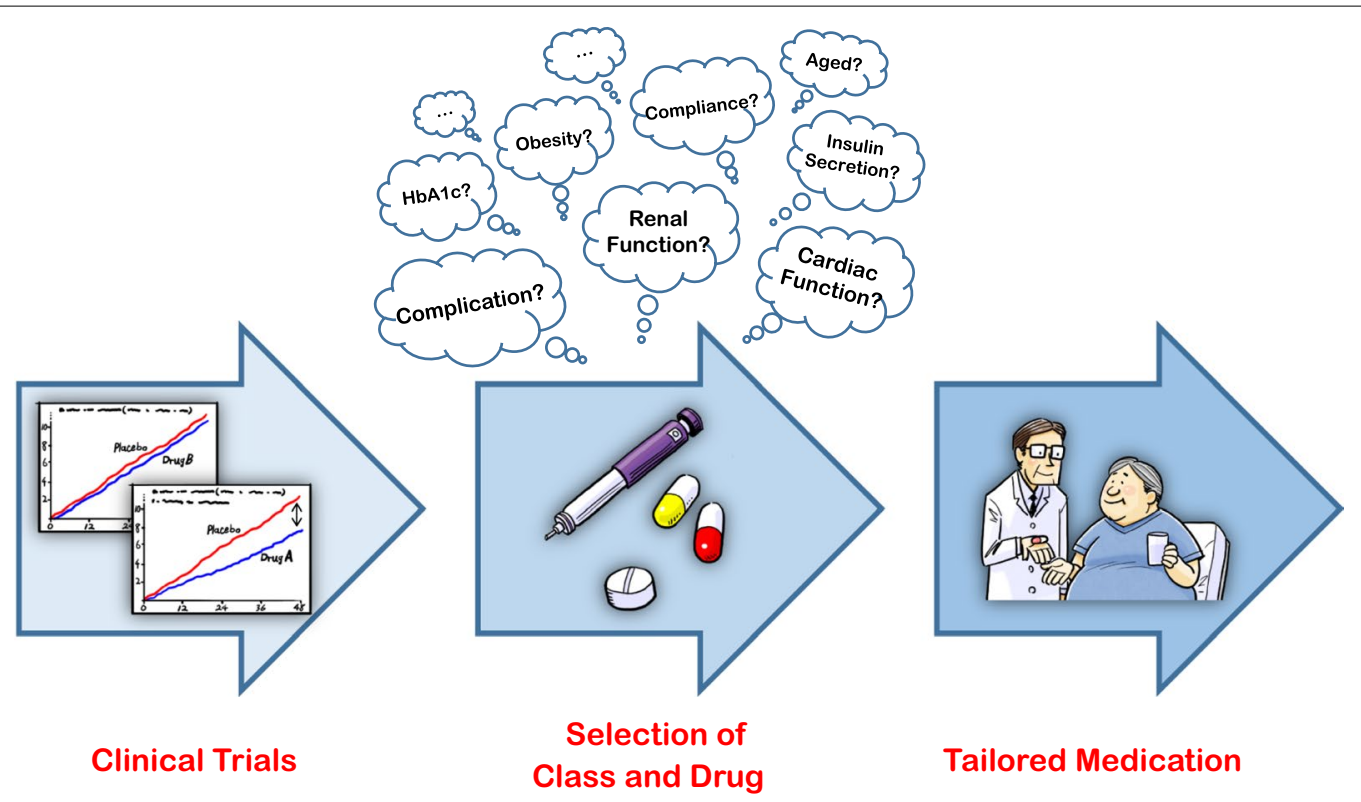

Fig. 1 The pathway from clinical trials to selecting tailored medication for patients with type 2 diabetes

comparing linagliptin with glimepiride, are still waiting. Although some pre-clinical and clinical studies demonstrated that linagliptin has unique and multiple cardiovascular protective actions [5], effects of linagliptin on vascular function as a key surrogate marker of cardiovascular risk remain to be controversial in clinical settings [6-8].

Linagliptin treatment did not increase the risk of hospitalization for heart failure (HF), but for the first time ever, was shown to be associated with a slight reduction in the risk. There appears to be a small but noticeable difference in the risk of hospitalization for HF associated with each DPP-4i relative to placebo between the CARMELINA (HR 0.90, 95\% CI 0.74-1.08) [1] and SAVORTIMI 53 (HR 1.27, 95\% CI 1.07-1.51) [9]. In addition to more severe renal impairment, the participants in the CARMELINA study had a higher frequency of a history of HF and the use of insulin than those in the SAVORTIMI 53 study. Although the possible risk of HF associated with DPP-4is remains controversial $[10,11]$, the results of the CARMELINA study enhanced clinical evidence that linagliptin treatment for a high cardiovascular and renal risk population at least did not affect the risk of HF-relate outcomes [12]. Thus, the study may strengthen the evidence for a class-effect of DPP-4is on safety, and also identify potential beneficial drug-effects for linagliptin on cardiovascular and renal systems. These findings may therefore provide important and unique evidence for linagliptin when choosing a glucose-lowering agents or even a DPP-4i.
Recent CVOTs with other classes of agent such as sodium-glucose cotransporter 2 (SGLT2) inhibitors and glucagon-like peptide-1 (GLP-1) receptor agonists, have also demonstrated unique and attractive results which may have had a major influence on decision-making in daily clinical practice regarding the choice of drug. SGLT2 inhibitors are known to reduce the risk of HF-related outcomes and delay the progression of nephropathy in a wide range of patients with T2D, while expectations of benefit on MACE appear to be higher in patients receiving secondary prevention of cardiovascular diseases [13]. On the other hand, GLP-1 receptor agonists predominantly show beneficial impacts on MACE and mortality, although this finding was not necessarily inconsistent between trials with the class [14]. Thus, recent CVOTs on newer glucose-lowering agents may have paid more attention to both the class-specific and possible drug-specific effects of those agents on cardiovascular and renal systems than that given to their glucose-lowering action. This has the potential to cause a paradigm shift in diabetes and even cardio-renal care. Furthermore, clinical trials targeting residual large populations who do not meet the artificial inclusion criteria of recent CVOTs will also reflect real-world evidence and increase the chance of applying this evidence into daily clinical practice. This could potentially lead to more appropriate decisions regarding the class and drug to be administered in a broader range of the population. These clinical trials will therefore become an important gateway for assisting with the selection of the class and individual drug for overall improvement in the treatment of T2D (Fig. 1). Based on 
the results shown in the clinical trials, we will be able to select more optimal class and drug according to the individual patients' clinical characteristics. This would lead to the desirable selection of glucose-lowering agents and 'Tailored Medication' in diabetes care.

\section{Abbreviations}

CVOT: cardiovascular outcome trial; DPP-4i: dipeptidyl peptidase-4 inhibitor; GLP-1: glucagon-like peptide-1; HF: heart failure; MACE: major adverse cardiovascular event; SGLT2: sodium-glucose cotransporter 2; T2D: type 2 diabetes.

\section{Authors' contributions}

AT wrote the draft of the article, which was then critically reviewed by KN. Both authors read and approved the final manuscript.

\section{Acknowledgements}

Authors thank Ms. Aya Yamada for her excellent secretarial assistance.

\section{Competing interests}

AT has received modest honorariums from Astellas Pharma Inc., AstraZeneca, Boehringer Ingelheim, Daiichi Sankyo Company, Ltd., Merck \& Co. Inc., Mitsubishi Tanabe Pharma Co., Novo Nordisk Pharma Ltd., Taisho Toyama Pharmaceutical Co., Ltd., and Takeda Pharmaceutical Company Ltd. KN has received honorariums from Astellas Pharma Inc., AstraZeneca, Eli Lilly Japan K.K., Ono Pharmaceutical Co., Ltd., Sanofi K.K., Takeda Pharmaceutical Company Ltd., Mitsubishi Tanabe Pharma Co., Boehringer Ingelheim, Bayer Yakuhin Ltd., Daiichi Sankyo Company, Ltd., Teijin Pharma Ltd., Merck \& Co. Inc.; research grants from Asahi Kasei Co., Astellas Pharma Inc., Mitsubishi Tanabe Pharma Co., Boehringer Ingelheim, Teijin Pharma Ltd.; scholarships from Novartis Pharma K.K, Astellas Pharma Inc., Takeda Pharmaceutical Company Ltd., Daiichi Sankyo Company, Ltd., AstraZeneca, Bristol-Myers Squibb.

\section{Availability of data and materials}

Not applicable.

\section{Consent for publication}

Not applicable.

Ethics approval and consent to participate

Not applicable.

\section{Funding}

This work was supported by the Mitsui Life Social Welfare Foundation.

\section{Publisher's Note}

Springer Nature remains neutral with regard to jurisdictional claims in published maps and institutional affiliations.

Received: 13 February 2019 Accepted: 19 February 2019

Published online: 28 February 2019

\section{References}

1. Rosenstock J, Perkovic V, Johansen OE, Cooper ME, Kahn SE, Marx N, Alexander JH, Pencina M, Toto RD, Wanner C, Zinman B, Woerle HJ, Baanstra D, Pfarr E, Schnaidt S, Meinicke T, George JT, von Eynatten M, McGuire DK, CARMELINA Investigators. Effect of linagliptin vs placebo on major cardiovascular events in adults with type 2 diabetes and high cardiovascular and renal risk: the CARMELINA randomized clinical trial. JAMA. 2018. https://doi.org/10.1001/jama.2018.18269 (Epub ahead of print).

2. Scheen AK. Cardiovascular effects of new oral glucose-lowering agents: DPP-4 and SGLT-2 inhibitors. Circ Res. 2018;122(10):1439-59.

3. Groop PH, Cooper ME, Perkovic V, Emser A, Woerle HJ, von Eynatten M. Linagliptin lowers albuminuria on top of recommended standard treatment in patients with type 2 diabetes and renal dysfunction. Diabetes Care. 2013;36(11):3460-8.

4. Marx N, Rosenstock J, Kahn SE, Zinman B, Kastelein JJ, Lachin JM, Espeland MA, Bluhmki E, Mattheus M, Ryckaert B, Patel S, Johansen OE, Woerle HJ. Design and baseline characteristics of the CARdiovascular outcome trial of LINAgliptin versus glimepiride in Type 2 diabetes (CAROLINA ${ }^{\circledR}$ ). Diab Vasc Dis Res. 2015;12(3):164-74.

5. Aroor AR, Manrique-Acevedo C, DeMarco VG. The role of dipeptidylpeptidase-4 inhibitors in management of cardiovascular disease in diabetes; focus on linagliptin. Cardiovasc Diabetol. 2018;17(1):59.

6. Koyama T, Tanaka A, Yoshida H, Oyama Jl, Toyoda S, Sakuma M, Inoue T, Otsuka Y, Node K. Comparison of the effects of linagliptin and voglibose on endothelial function in patients with type 2 diabetes and coronary artery disease: a prospective, randomized, pilot study (EFFORT). Heart Vessels. 2018:33(8):958-64.

7. Jax T, Stirban A, Terjung A, Esmaeili H, Berk A, Thiemann S, Chilton R, von Eynatten M, Marx N. A randomised, active- and placebo-controlled, three-period crossover trial to investigate short-term effects of the dipeptidyl peptidase-4 inhibitor linagliptin on macro- and microvascular endothelial function in type 2 diabetes. Cardiovasc Diabetol. 2017;16(1):13.

8. Tripolt NJ, Aberer F, Riedl R, Url J, Dimsity G, Meinitzer A, Stojakovic T, Aziz F, Hödl R, Brachtl G, Strunk D, Brodmann M, Hafner F, Sourij H. Effects of linagliptin on endothelial function and postprandial lipids in coronary artery disease patients with early diabetes: a randomized, placebo-controlled, double-blind trial. Cardiovasc Diabetol. 2018;17(1):71.

9. Scirica BM, Bhatt DL, Braunwald E, Steg PG, Davidson J, Hirshberg B, Ohman P, Frederich R, Wiviott SD, Hoffman EB, Cavender MA, Udell JA, Desai NR, Mosenzon O, McGuire DK, Ray KK, Leiter LA, Raz I, SAVOR-TIMI 53 Steering Committee and Investigators. Saxagliptin and cardiovascular outcomes in patients with type 2 diabetes mellitus. N Engl J Med. 2013;369(14):1317-26.

10. Pocock SJ, McMurray JJV, Collier TJ. Statistical controversies in reporting of clinical trials: part 2 of a 4-part series on statistics for clinical trials. J Am Coll Cardiol. 2015;66(23):2648-62.

11. Li L, Li S, Deng K, Liu J, Vandvik PO, Zhao P, Zhang L, Shen J, Bala MM, Sohani ZN, Wong E, Busse JW, Ebrahim S, Malaga G, Rios LP, Wang Y, Chen Q, Guyatt GH, Sun X. Dipeptidyl peptidase-4 inhibitors and risk of heart failure in type 2 diabetes: systematic review and meta-analysis of randomised and observational studies. BMJ. 2016;352:1610.

12. McGuire DK, Alexander JH, Johansen OE, Perkovic V, Rosenstock J, Cooper ME, Wanner C, Kahn SE, Toto RD, Zinman B, Baanstra D, Pfarr E, Schnaidt S, Meinicke T, George JT, von Eynatten M, Marx N, CARMELINA Investigators. Linagliptin effects on heart failure and related outcomes in individuals with type 2 diabetes mellitus at high cardiovascular and renal risk in CARMELINA. Circulation. 2019;139(3):351-61.

13. Zelniker TA, Wiviott SD, Raz I, Im K, Goodrich EL, Bonaca MP, Mosenzon O, Kato ET, Cahn A, Furtado RHM, Bhatt DL, Leiter LA, McGuire DK, Wilding JPH, Sabatine MS. SGLT2 inhibitors for primary and secondary prevention of cardiovascular and renal outcomes in type 2 diabetes: a systematic review and meta-analysis of cardiovascular outcome trials. Lancet. 2019:393(10166):31-9.

14. Li Y, Rosenblit PD. Glucagon-like peptide-1 receptor agonists and cardiovascular risk reduction in type 2 diabetes mellitus: is it a class effect? Curr Cardiol Rep. 2018;20(11):113. 